\title{
Impact of Anthropogenic Disturbance on Native and Invasive Trypanosomes of Rodents in Forested Uganda
}

\author{
Johanna S. Salzer, ${ }^{1,2,3}$ C. Miguel Pinto, ${ }^{4,5}$ Dylan C. Grippi, ${ }^{1}$ Amanda Jo Williams-Newkirk, ${ }^{1,2,6}$ \\ Julian Kerbis Peterhans, ${ }^{7,8}$ Innocent B. Rwego, ${ }^{2,9,10}$ Darin S. Carroll, ${ }^{2,3}$ \\ and Thomas R. Gillespie $e^{1,2,9}$
}

\footnotetext{
${ }^{1}$ Program in Population Biology, Ecology, and Evolution, Emory University, 400 Dowman Dr., Math and Science Center 5th Floor, Atlanta, GA 30322

${ }^{2}$ Department of Environmental Sciences, Emory University, Atlanta, GA 30322

${ }^{3}$ Poxvirus and Rabies Branch, Division of High-Consequence Pathogens and Pathology, Centers for Disease Control and Prevention, Atlanta, GA 30333

${ }^{4}$ Department of Mammalogy and Sackler Institute for Comparative Genomics, American Museum of Natural History, New York, NY 10024

${ }^{5}$ Instituto de Ciencias Biológicas, Escuela Politécnica Nacional, PO Box 17-01-2759, Quito, Ecuador

${ }^{6}$ Rickettsial Zoonoses Branch, Division of Vector-borne Diseases, Centers for Disease Control and Prevention, Atlanta, GA 30333

${ }^{7}$ College of Professional Studies, Roosevelt University, Chicago, IL 60605

${ }^{8}$ Division of Mammals, Field Museum of Natural History, Chicago, IL 60605

${ }^{9}$ Department of Environmental Health, Rollins School of Public Health, Emory University, Atlanta, GA 30322

${ }^{10}$ Department of Biological Sciences, Makerere University, Kampala, Uganda
}

\begin{abstract}
Habitat disturbance and anthropogenic change are globally associated with extinctions and invasive species introductions. Less understood is the impact of environmental change on the parasites harbored by endangered, extinct, and introduced species. To improve our understanding of the impacts of anthropogenic disturbance on such host-parasite interactions, we investigated an invasive trypanosome (Trypanosoma lewisi). We screened 348 individual small mammals, representing 26 species, from both forested and non-forested habitats in rural Uganda. Using microscopy and PCR, we identified $18 \%$ of individuals (order Rodentia) as positive for trypanosomes. Further phylogenetic analyses revealed two trypanosomes circulating-T. lewisi and T. varani. T. lewisi was found in seven species both native and invasive, while T. varani was identified in only three native forest species. The lack of $T$. varani in non-forested habitats suggests that it is a natural parasite of forest-dwelling rodents. Our findings suggest that anthropogenic disturbance may lead to spillover of an invasive parasite (T. lewisi) from non-native to native species, and lead to local co-extinction of a native parasite (T. varani) and native forest-dwelling hosts.
\end{abstract}

Keywords: disease, small mammals, forest fragment, Kibale National Park, Praomys, Rattus, Trypanosoma lewisi, Trypanosoma varani

\section{INTRODUCTION}

The views expressed in this paper are solely those of the authors and do not represent those of the CDC, US Government, or any other entity which the authors may be affiliates.

Correspondence to: Thomas R. Gillespie, e-mail: thomas.gillespie@emory.edu
As habitats experience anthropogenic disturbance, small mammal community structure is altered. Changes in community structure may also affect the prevalence of 
parasites that infect small mammal hosts (Keesing et al. 2006; Randolph and Dobson 2012; Young et al. 2013; McCauley et al. 2015). In some cases, such changes have resulted in losses of host populations and subsequently the parasites they harbor (Koh et al. 2004; Altizer et al. 2007; Chasar et al. 2009; Dunn et al. 2009; Bush et al. 2013). As ecological theory predicts, the rates of spread and occurrence of parasites of these reduced populations should decline as the host population decreases in size and density (Anderson and May 1979; May and Anderson 1991). Additionally, parasites are considered to play a key role in food web structure and the loss of parasites may be detrimental to the stability of the ecosystem (Dunne et al. 2013). Alternatively, anthropogenic changes may also lead to introductions of invasive, disturbance-tolerant species, and their associated parasites (Verneau et al. 2011). Habitat loss, specifically in the form of deforestation, has been linked to a decline in large predators leading to a subsequent increase in both rodent populations and the diseases they harbor (Young et al. 2014). Pathogen emergence and extinction are considered to be dependent on the complex interactions among a specific pathogen, host, vector, and habitat (Salkeld et al. 2013). A native pathogen may be driven to extinction in disturbed habitats where opportunistic, generalist species are less competent hosts (Pedersen et al. 2007), while a more generalist pathogen will thrive in this same environment.

Trypanosomes are protozoan blood-borne parasites that are known to infect humans, wildlife, and domestic animals. There are at least 43 recorded trypanosome species infecting 125 rodent species throughout the world (Hoare 1972). Despite the large number of trypanosomes associated with wild rodents, their infection dynamics, molecular characteristics, zoonotic potential, and pathogenicity in their natural hosts have received little attention (Sato et al. 2003). Our knowledge of the diversity of species within the genus Trypanosoma, as well as the host-specificity of these parasites and their vectors, is a growing field of study (e.g., Hamilton et al. 2007; Averis et al. 2009). Trypanosoma lewisi, primarily transmitted by the rat flea (Xenopsylla cheopis), is closely associated with peridomestic rodents of the genus Rattus (e.g., Rattus rattus, and R. norvegicus), which are considered primarily responsible for the global distribution of T. lewisi (Hoare 1972). The global spread of T. lewisi has mirrored that of its host and vector, which explains this parasite's broad global distribution (Pinto et al. 2006; Wyatt et al. 2008; Adams et al. 2010). Although other rodents are susceptible to T. lewisi, the occurrence of this parasite is often associated with pathogen spillover from Rattus spp. to native species (Wyatt et al. 2008; Dobigny et al. 2011; Milocco et al. 2013). Native trypanosomes are known to infect small mammals, but do not occupy as broad of a host range as the invasive parasite, T. lewisi (Dobigny et al. 2011).

Our study investigated trypanosomes of small mammals of western Uganda in forest habitats within Kibale National Park (KNP), and less-forested habitats outside the protected boundaries of KNP. Our study aimed to specifically investigate coexistence of invasive and native parasites and further understand the distribution of these parasites among host communities and habitat types. We hypothesized that the small mammals of western Uganda, like other areas of Africa, would be infected with the invasive parasite T. lewisi as a consequence of pathogen spillover and species invasion in disturbed habitats. Additionally, if other native species of trypanosomes are identified, these parasites were hypothesized to be more closely associated with native small mammals and less disturbed habitats. We screened for trypanosomes using both microscopy and molecular techniques to determine parasite prevalence. The results of this work contribute to our understanding of host specificity of trypanosomes circulating among small mammals in habitats experiencing varied anthropogenic disturbance.

\section{Materials and Methods}

\section{Study Area}

$\mathrm{KNP}$ is a $795 \mathrm{~km}^{2}$ mid-elevation tropical moist forest located in the foothills of the Rwenzori Mountains in western Uganda [0 13'-0 41 $\mathrm{N}, 30^{\prime} 19^{\prime}-30^{\prime} 22^{\prime}$ E] (Hartter 2009). KNP was designated as a national park in 1993, and is protected by the Uganda Wildlife Authority (Struhsaker 1997). Portions of KNP were logged at varied intensities in the 1960s resulting in a series of contiguous forest compartments recovering from various logging intensities (Chapman et al. 2000). Our sampling sites were divided into two broad categories: forested and non-forested habitats. Forested habitats consisted of four less disturbed collection sites within the boundaries of KNP (relatively pristine, lightly logged, heavily logged, and forest edge). The non-forested habitats were outside KNP and included two forest fragments and various human settlements (i.e., homes, trading-centers, research field station, and village gardens) experiencing more extreme anthropogenic dis- 
turbance than areas within KNP. The degree and nature of disturbance have been determined for these locations using methods previously described (Gillespie and Chapman 2006).

\section{Animal Collection and Identification}

Animal collection was approved by the Uganda Wildlife Authority, the Uganda National Council for Science and Technology, local authorities (Local Chairman), and homeowners, as well as IACUC from Emory University (\#062-2009) and the Centers for Disease Control and Prevention (\#1768).

From May through July 2009, animals from forested areas and forest fragments were collected using a trapping web containing 153 traps total. Each web was $200 \mathrm{~m}$ in diameter containing a total of 148 Sherman traps $\left(3 \times 3.5 \times 9^{\prime \prime}\right.$, H.B. Sherman Traps, Inc., Tallahassee, FL) (Mills et al. 1999). Additionally, five Tomahawk traps $\left(19 \times 6 \times 6^{\prime \prime}\right.$, Tomahawk Live Trap Co., Tomahawk, WI $)$ were set at the center and $50 \mathrm{~m}$ in the cardinal directions and the center. We used pitfall traps in forested sites but only one individual was collected via this method. We collected in human dwellings (10 traps per home) where the homeowner was interested in pest removal. Traps used in webs and a majority of the human dwellings were consistently baited in the evenings with a millet and peanut butter mixture and collected at sunrise to prevent inadvertent death due to exposure. A few dwellings kept traps and baited them with a variety of kitchen food waste; these samples were included in the overall human dwellings samples. Trapping webs were operated for three consecutive nights on each trapping occasion as described in Salzer et al. (2015). All sites were sampled twice except the forest edge and heavily logged forest sites, which were sampled once.

Animals were removed from traps, anesthetized with $5 \%$ isoflurane inhalation, and blood was collected via cardiocentesis. Animals were humanely euthanized and photographs and morphometric data were collected (Delany 1975; Carleton and Musser 2005). Necropsies were performed and spleen samples were collected. Skulls and blood smears were retained from a subset of animals that were considered morphologically representative of the larger sampling. Molecular identification was necessary for individuals indistinguishable by external morphology and was conducted by sequencing of the first half of the cytochrome B gene (480 bp) (Peppers et al. 2002).

\section{Trypanosome Detection and Differentiation}

Initially, we screened a subset of animals $(n=103)$ for the presence of trypanosomes using microscopy. Two thin smear slides were made from blood from each animal and fixed using $100 \%$ methanol and stained in a $10 \%$ giemsa solution for $20 \mathrm{~min}$. Smears were examined using standard light microscopy with phase contrast using high magnification ( $\times 1000$ oil immersion). Approximately, 100 fields of view were observed per slide. Presence or absence was determined by inspecting for trypomastigotes in the blood smear.

We further screened all animals $(n=348)$ for the presence of Trypanosoma spp. in splenic DNA extracted using EZ1DNA tissue kit (Qiagen, Valencia, CA). The $18 \mathrm{~S}$ rRNA gene fragment was amplified following previously described nested PCR methods using external primersTRY927F and TRY927R, and for the internal primersSSU561F and SSU561R (Noyes et al. 2002).

The positive PCR products were purified with ExoSAP-IT (Affymetrix, Inc., Santa Clara, CA), and then sequenced using the internal primers SSU561F and SSU561R with the ABI Big Dye chemistry on an ABI 3730xl DNA Analyzer automatic sequencer (Applied Biosystems, Inc., Foster City, CA). We followed the phylogenetic approach implemented by Pinto et al. (2012) and Cottontail et al. (2014) to align the short sequences of the 18S rRNA with a more comprehensive set of longer sequences and concatenated it with another phylogenetically informative gene (Cottontail et al. 2014). We constructed an alignment of the new sequences using the Geneious Alignment tool using default parameters in the software Geneious (Drummond et al. 2010), and reduced the matrix to contain only unique sequences. We then combined the newly generated data with the datasets for the $18 \mathrm{~S}$ rRNA and gGAPDH genes (Hamilton et al. 2007) using the Consensus Align tool in Geneious. The alignment was checked and corrected manually. A maximum likelihood tree was constructed using RAxML (Stamatakis et al. 2005), and node support was estimated by 1000 bootstrap pseudoreplicates. To corroborate the identifications of the trypanosomes detected, we ran the delimitation analysis Poisson tree processes (PTPs; Zhang et al. 2013), with the maximum likelihood tree using 500,000 MCMC generations and a thinning of 100 . 


\section{Data Analysis}

We first determined if there were dominant small mammal species that were more closely associated with either forest or non-forest habitats, using Fisher's exact test. We then determined if certain species of trypanosomes were significantly associated with either forest or non-forested habitats using $\chi^{2}$ test and Fisher's exact for small samples. We further identified which specific rodent hosts were susceptible to trypanosome infections compared to the small mammal community as a whole using $\chi^{2}$ test and Fisher's exact for small samples. Statistical analyses were performed using the stats package on the $\mathrm{R}$ version 3.0.1 ( $\mathrm{R}$ Core Team 2013).

\section{Results}

\section{Animal Collection and Identification}

In total, 348 individual small terrestrial mammals were collected in and around KNP, representing 26 species (Table 1). Representative skull samples were identified and catalogued at the Field Museum in Chicago, IL (\#210384210540).

Praomys misonnei and Hylomyscus stella were more closely associated with forested habitats within KNP compared to other small mammal species. Adult members of two species of the genus Praomys (e.g., $P$. jacksoni and $P$. misonnei) were identified using cranio-dental features and

Table 1. Prevalence of Trypanosomes Among Host Species.

\begin{tabular}{|c|c|c|c|}
\hline \multirow[t]{2}{*}{ Species } & \multirow[t]{2}{*}{ Number tested } & \multicolumn{2}{|c|}{$\begin{array}{l}\text { Number infected } \\
\text { (\% prevalence) }\end{array}$} \\
\hline & & T. lewisi & T. cf. varani \\
\hline Arvicanthus niloticus & 1 & 0 & 0 \\
\hline Crocidura dolichura & 1 & 0 & 0 \\
\hline Crocidura fuscomurina & 1 & 0 & 0 \\
\hline Crocidura cf. littoralis & 1 & 0 & 0 \\
\hline Crocidura maurisca & 1 & 0 & 0 \\
\hline Crocidura nigrofusca & 3 & 0 & 0 \\
\hline Crocidura olivieri & 6 & 0 & 0 \\
\hline Dasymys incomtus & 1 & 0 & 0 \\
\hline Dendromus cf. mystacalis & 1 & 0 & 0 \\
\hline Gerbilliscus kempi ruwenzorii & 7 & 0 & 0 \\
\hline Grammomys sp. & 1 & 0 & 0 \\
\hline Graphiurus murinus & 1 & $1(100)$ & 0 \\
\hline Hybomys lunaris & 5 & $2(40.0)$ & 0 \\
\hline Hylomyscus stella & 52 & 0 & $6(12.0)$ \\
\hline Lemniscomys striatus & 3 & $3(100)$ & 0 \\
\hline Lophuromys aquilus & 48 & $1(2.0)$ & 0 \\
\hline Malacomys longipes & 4 & 0 & 0 \\
\hline Mastomys natalensis & 1 & 0 & 0 \\
\hline Mus bufo & 2 & 0 & 0 \\
\hline Mus grata & 27 & 0 & 0 \\
\hline Mus triton & 6 & $5(83.0)$ & 0 \\
\hline Oenomys hypoxanthus & 3 & 0 & 0 \\
\hline Praomys jacksoni & 104 & $25(24.0)$ & $5(4.8)$ \\
\hline Praomys misonnei & 23 & 0 & $2(9.0)$ \\
\hline Rattus rattus & 44 & $13(30.0)$ & 0 \\
\hline Scutisorex somereni & 1 & 0 & 0 \\
\hline Total & 348 & $50(14.4)$ & $13(4.0)$ \\
\hline
\end{tabular}

In total, 348 individual small mammals, representing 26 species, were collected from in and around Kibale National Park in western Uganda. Each individual was tested for both Trypanosoma lewisi and T. varani. Prevalence of trypanosome infection varied among host species. 
confirmed molecularly. These two species co-occurred within the forested habitats of KNP but only P. jacksoni was found in areas outside KNP (Fig. 1). The association between $P$. misonnei and areas within KNP was significant when compared to $P$. jacksoni (Fisher's exact test, $P<0.001)$. P. misonnei appear to be more susceptible to habitat disturbance compared to P. jacksoni, which occur in forested and non-forested areas such as human dwellings. $H$. stella was one of the most abundant species collected during this study and was commonly found within forested habitats but not exclusively (Fig. 1), it was strongly associated with forested habitats (Fisher's exact test, $P=0.002$ ).

Human dwellings, areas within homes, surrounding gardens, trading centers, and the research station were dominated by $R$. rattus. This species was more closely associated with this highly disturbed environment than all other habitats. Of all the $R$. rattus collected in this study ( $n=44)$, all but one individual was found within human dwellings.

\section{Trypanosome Detection and Differentiation}

Using light microscopy, 18 of the blood smears $(n=103)$ were positive for trypanosomes. All 348 animals were screened for trypanosome DNA using the 18S rRNA gene PCR assay. Sixty-three individuals, all rodents, representing $17.5 \%$ of the total collected specimens, were positive by PCR. All individuals positive by microscopy were also PCR positive. In contrast, three individuals were negative by microscopy, but determined PCR positive. The phylogenetic analysis of the newly generated $18 \mathrm{~S}$ rRNA sequences integrated with comprehensive dataset of $18 \mathrm{~S}$ rRNA and gGAPDH genes, coupled with the PTP species delimitation analysis revealed that 50 individuals were positive for $T$. lewisi and 13 individuals were positive for $T$. varani, a parasite belonging to the lizard-hosted clade of trypanosomes (Table 1; Fig. 2). Standard PCR does not allow for the quantification of infection intensity within individuals.

Trypanosoma varani infection among small mammals occurred at low prevalence (3.7\%) overall and was significantly restricted to forested areas within KNP (Fisher's exact test, $P<0.001$; Fig. 3). This parasite was restricted to three native, forest-dwelling rodent species: $P$. jacksoni, P. misonnei, and H. stella (Table 1) (Delany 1975). Subsequently, using $\chi^{2}$ test with Yates continuity correction, we found that $T$. varani prevalence among H. stella $(P=0.006$, $\left.\chi^{2}=8.0\right)$ was significantly higher compared to other species, but no association was found with P. jacksoni and $P$. misonnei.

Trypanosoma lewisi infections were equally prevalent in areas within and outside KNP with no association with either forested or non-forested areas (Fig. 3). T. lewisi was identified in seven rodent species. P. jacksoni was the only host species of both T. varani $(n=5)$ and T. lewisi $(n=25$; Table 1). Several rodent species infected with T. lewisi (Table 1) were found to have significantly higher prevalence of infection when compared to all other species- $R$. rattus $(P=0.005)$, Lemniscomys striatus $(P=0.003)$, Mus triton $(P=0.001)$, and $P$. jacksoni $(P=0.001)$. In contrast, Lophuromys aquilus was found to have a significant lower prevalence compared to all other species $(P=0.007)$. No

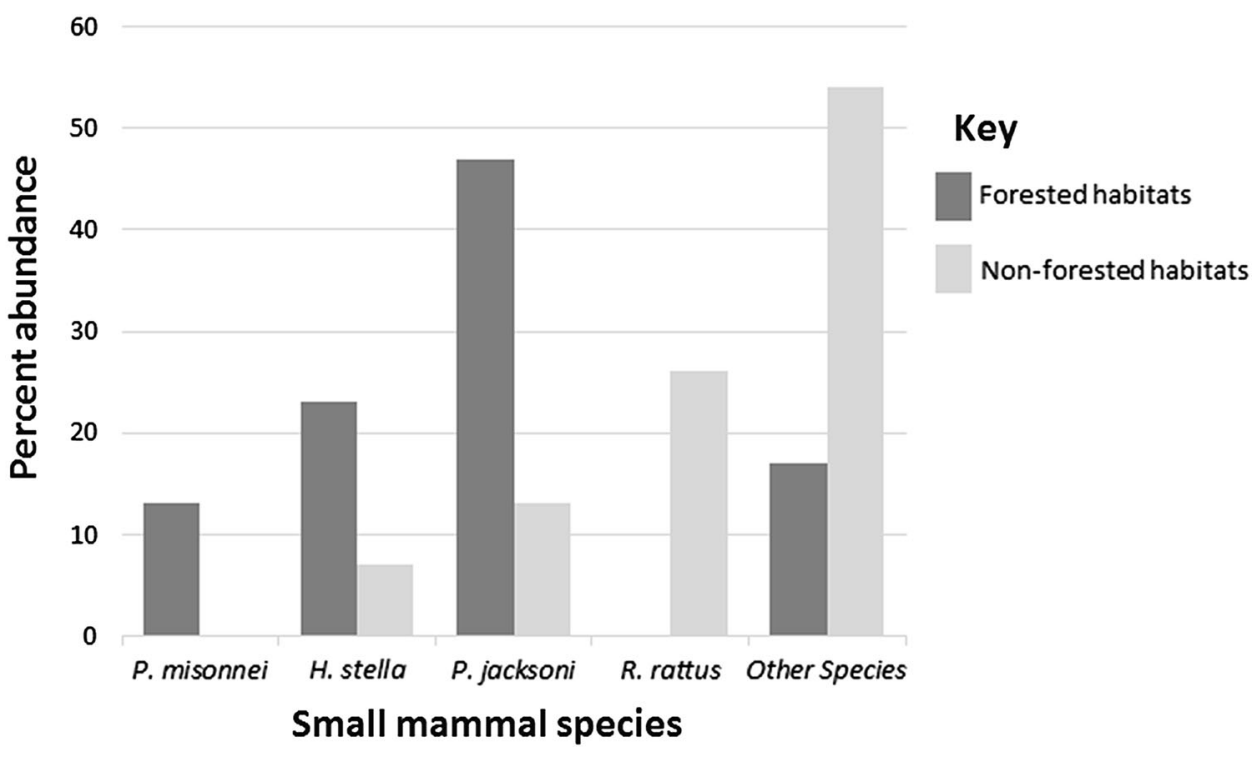

Figure 1. Relative abundance of Praomys jacksoni, P. misonnei, Hylomyscus stella, Rattus rattus, and all other individuals from either within the protected, forested areas of Kibale National Park in western Uganda or in the more disturbed, non-forested areas outside the park. 


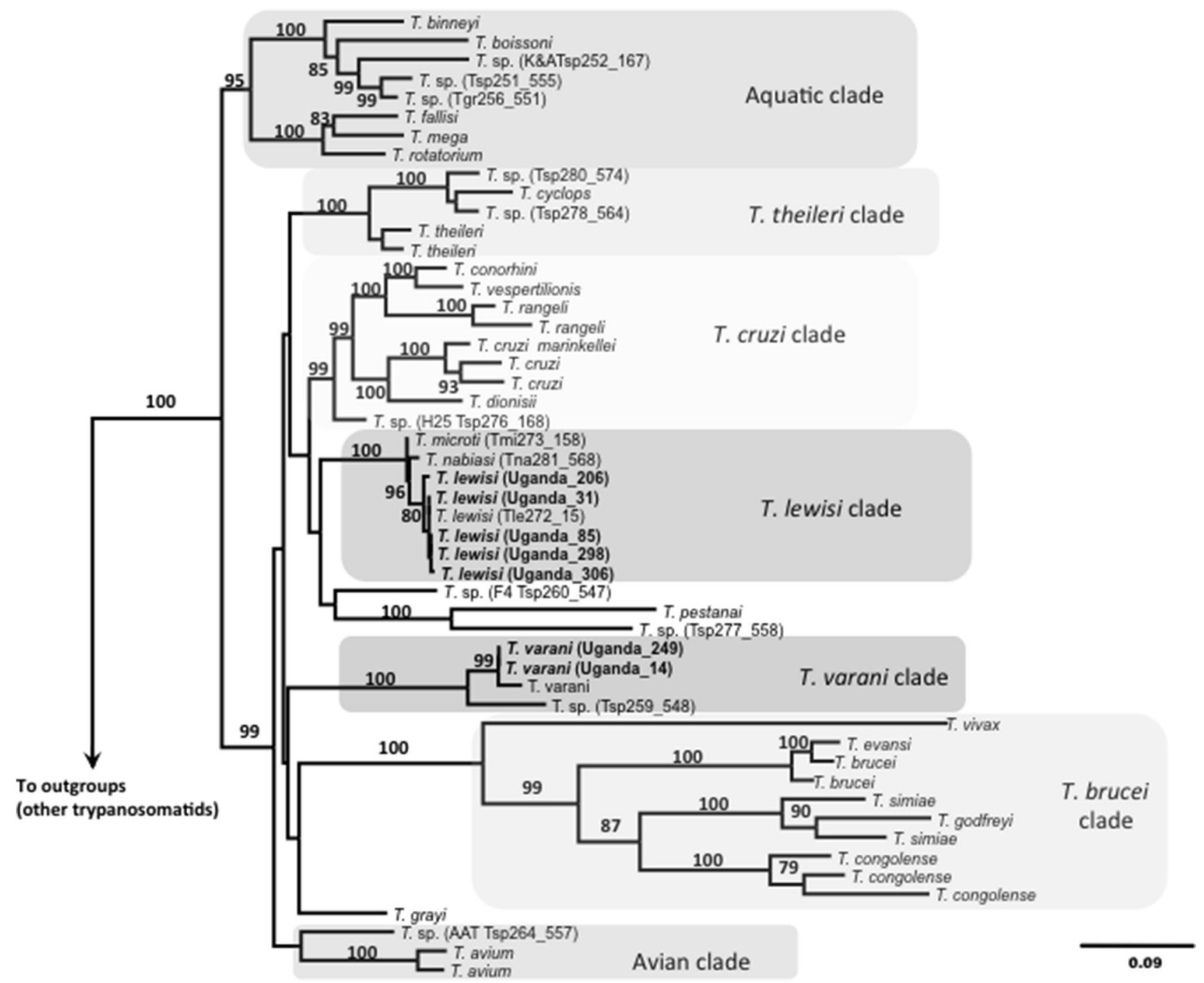

Figure 2. Maximum likelihood tree of a matrix of concatenated 18S rRNA and gGAPDH gene sequences of trypanosomes (Hamilton et al. 2007) with sequences generated in this study. Numbers on branches are bootstrap support values greater than 75 . Tip labels correspond to scientific name of trypanosomes, in parentheses are the code of the sequences in the matrix by Hamilton et al. (2007) or the codes assigned for new sequences, respectively, followed by the vertebrate: invertebrate hosts. Codes in bold represent the sequences generated in this study; 'uh' represent unknown host.

differences were noted between T. lewisi infection and $H y$ bomys lunaris and Graphiurus murinus, which may be due to the limits of the small sample size of these species. Further investigations of the habitat variables and the prevalence of these parasites was not conducted because of the limited sample size, low prevalence, and lack of sample replicates.

\section{DisCUSSION}

In western Uganda, three native forest-dwelling small mammal species associated with forested habitats are found to be positive for a newly identified trypanosome (T. varani). Although this trypanosome was found to infect a disturbance-tolerant species, it is absent from areas outside KNP. This suggests possible alterations in the presence or abundance of a necessary vector and/or competent host or possibly competitive exclusion of $T$. varani by $T$. lewisi. Additionally, the occurrence of $P$. misonnei and $H$. stella appears to play a key role in the maintenance of $T$. varani within KNP. This association suggests that these two disturbance-intolerant rodent species as competent hosts of this newly identified native trypanosome. The impacts of habitat disturbance on this host-parasite interaction may 


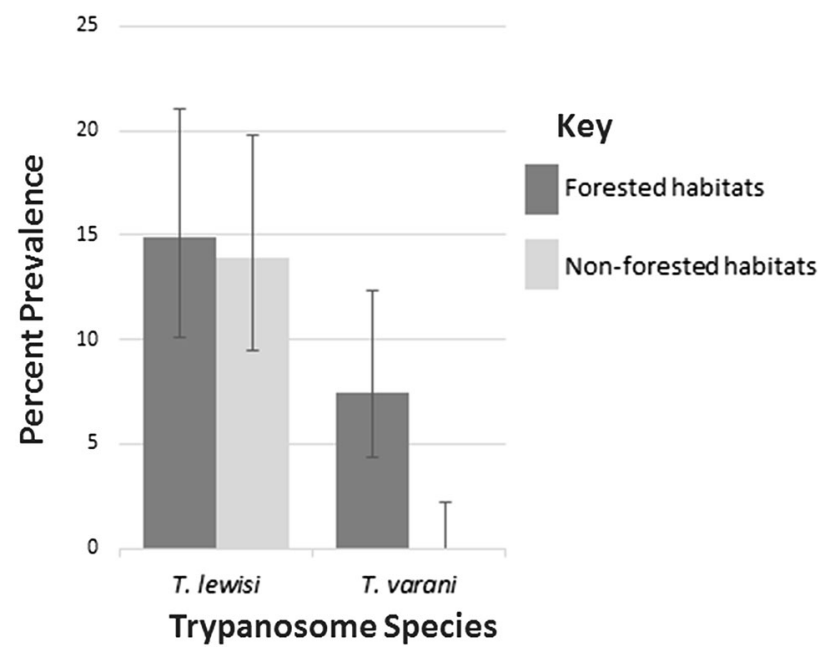

Figure 3. Prevalence of rodent-borne trypanosomes in forested areas within Kibale National Park and more disturbed areas outside the park. Prevalence of Trypanosoma lewisi and T. varani among all animals are shown.

synergistically drive local extinction of the hosts ( $P$. misonnei and H. stella) and subsequently a local extinction of the parasite.

We were limited in our analysis by the low prevalence of trypanosomes and small overall sample size among certain rodent species. A larger sampling effort is needed to examine the impact of host diversity on trypanosome prevalence in the absence of habitat disturbance in KNP. We believe that future studies of trypanosomes in and around KNP may provide information to further understand the relationship between diversity and disease.

Our identification of $T$. varani is similar to recently identified rodent trypanosomes from other areas of Africa. Work conducted in Niger identified a single Mastomys natalensis infected with a trypanosome considered a sister taxa of T. varani (Dobigny et al. 2011). Although not molecularly confirmed, previous studies in Kenya have identified two phenotypically different trypanosomes infecting P. jacksoni (Wanyonyi et al. 2011). Additional phylogenetic analysis is needed to understand how related the $T$. varani identified in our study is to other historical and newly identified trypanosomes. The natural history of T. varani is minimally understood and even less is known about the involvement of rodents in its lifecycle. This parasite was first described in 1908 from a Nile monitor lizard (Varanus niloticus) collected in Sudan (Wenyon 1908). Since this time it has been identified in other reptilian species, such as the ball python (Python reginus) (Sato et al. 2009). It is also possible this parasite naturally occurs in a native reptilian species within KNP, possibly pythons, which do exist in KNP (Struhsaker 1997). Due to the known prey-predator interactions among pythons and rodents, the identification of $T$. varani in rodents may identify rodents as a critical host in the life cycle of this parasite. Pathogen spill-over from rodents to snakes could provide another explanation for the identification of this parasite in both rodents and reptiles, although the reverse may be less likely given the prey-predator outcomes between these animals.

Previous studies found $T$. lewisi almost exclusively associated with $R$. rattus and rarely associated with other native African forest species (Dobigny et al. 2011). In contrast, in addition to identifying T. lewisi among $R$. rattus, we found six native rodent species infected with $T$. lewisi. These findings broaden our knowledge of the hostspecificity of T. lewisi (Pumhom et al. 2014). Our work parallels recent studies demonstrating that rodent trypanosomes have broad host ranges, but experience variable distributions across landscapes (Averis et al. 2009; Dobigny et al. 2011; Milocco et al. 2013). It may be possible for coinfection to occur with these parasites, although with our methods we were not able to detect coinfection. Additional studies will need to properly identify host competency and coinfection of trypanosomes among small mammals in KNP.

Praomys jacksoni appears to play a primary role in maintaining $T$. lewisi in western Uganda and specifically in forest habitats where $R$. rattus are absent. $R$. rattus in western Uganda is the dominant species in areas of extreme disturbance (human dwellings) and considered the primary rodent host of T. lewisi (Dobigny et al. 2011). Our study identified T. lewisi occurring in habitats free of Rattus populations. Although T. lewisi was likely introduced by $R$. rattus, it is now maintained in other native rodent populations free of $R$. rattus. A spillover event of invasive $T$. lewisi appears to have occurred prior to 2009 that has resulted in its persistence in native rodents in forested and non-forested areas. The impact and pathogenicity of this parasite on native African rodents are unknown. Future laboratory animal studies would be needed to understand the impact of trypanosomes on rodent health.

Multiple genera of fleas serve as vectors for T. lewisi. This broad vector range likely aids spillover of $T$. lewisi into native host species (Molyneux 1969). As vector-trypanosome associations were beyond the scope of our study, we can only speculate as to how the behavior of the unknown vector may impact parasitism among rodent pop- 
ulations. Thus, we cannot rule out that the pattern of rodent species infected with either trypanosome in this study is not influenced by the vector's host-preference more than parasite-host compatibility.

Although T. lewisi is primarily associated with rodent infections, human cases of disease have been reported (Verma et al. 2011). Rare human infections have been reported and most occurred in infants or immunosuppressed adults (Truc et al. 2013). The high prevalence of T. lewisi in rodents in human dwellings in our study may pose a previously unidentified public health risk, particularly in western Uganda. The impact of $T$. varani on both rodent and human health is unknown.

Previous work examining small mammals in KNP found that host taxonomy and natural history as more influential on general parasite occurrence than any ecological factor examined (Salzer et al. 2015). This previous work was conducted on a subset of the samples examined in our current study and examined a large variety of parasites to a crude level. Our current study used a finer scale of parasite identification and further supports this previously identified relationship between host taxonomy and parasite dynamics.

Parasites play a primary role in food web structure and maintenance of diversity within ecosystems (Dunne et al. 2013). Parasite extinctions may have a negative impact on the health of larger free-living species (Dobson et al. 2008). The results of our study suggest that habitat disturbance in western Uganda has led to local extinctions of P. misonnei and subsequently a loss of its native trypanosome, T. varani. Although this trypanosome is found to infect other, more disturbance-tolerant host species (i.e., P. jacksoni), the presence of this parasite is associated with the presence of $P$. misonnei. This suggests forest-dwelling rodent species possibly play a significant role in maintenance of this parasite. Our work provides preliminary evidence of local co-extinction of host and parasite linked with a disruption in ecosystem structure, although the mechanisms of causation were impossible to identify in our study.

\section{Acknowledgments}

This research was supported in part by the Emory Global Health Institute, Emory University Environmental Science Department, and the appointment of J.S.S. to the Research Participation Program administered by Oak Ridge Institute for Science and Education (ORISE) through an Interagency
Agreement with CDC. The authors thank the Uganda Wildlife Authority, Uganda National Council for Science and Technology, Makerere University Biological Field Station and local authorities for permission to conduct this study. The authors are thankful to J. de Roode for his encouragement and interests in investigating blood-borne pathogens. The authors thank S. Ockers, C. Akora, and I. Mwesige who provided valuable assistance in the field and $\mathrm{K}$. Cross for assistance in the laboratory. The authors also thank S. L. Perkins, J. N. Mills, I. K. Damon, W. Stanley, U. Kitron, R. R. Lash, and S. P. Montgomery for helpful comments, logistical, and/or analytical assistance.

\section{References}

Adams ER, Hamilton PB, Gibson WC (2010) African trypanosomes: celebrating diversity. Trends in Parasitology 26:324-328

Altizer S, Nunn CL, Lindenfors P (2007) Do threatened hosts have fewer parasites? A comparative study in primates Journal of Animal Ecology 76:304-314

Anderson RM, May RM (1979) Population biology of infectious diseases: Part I. Nature 280:361-367

Averis S, Thompson RCA, Lymbery AJ, Wayne AF, Morris KD, Smith A (2009) The diversity, distribution and host-parasite associations of trypanosomes in Western Australian wildlife. Parasitology 136:1269-1279

Bush SE, Reed M, Maher S (2013) Impact of forest size on parasite biodiversity: implications for conservation of hosts and parasites. Biodiversity and Conservation 22:1391-1404

Carleton MD, Musser GG (2005) Order Rodentia. In: Mammal Species of the World: A Taxonomic and Geographic Reference, Wilson DE, Reeder DM (editors), Baltimore, MD: Johns Hopkins University Press, pp 745-752

Chapman CA, Balcomb SR, Gillespie TR, Skorupa JP, Struhsaker TT (2000) Long-term effects of logging on African primate communities: a 28-year comparison from Kibale National Park, Uganda. Conservation Biology 14:207-217

Chasar A, Loiseau UC, Valkiunas G, Iezhova T, Smith TB, Sehgal RNM (2009) Prevalence and diversity patterns of avian blood parasites in degraded African rainforest habitats. Molecular Ecology 18:4121-4133

Cottontail VM, Kalko EKV, Cottontail I, Wellinghausen N, Tschapka M, Perkins SL, et al. (2014) High local diversity of Trypanosoma in a common bat species, and implications for the biogeography and taxonomy of the T. cruzi clade. PLoS One 9:e108603

Delany MJ (1975) The Rodents of Uganda, London, UK: Trustees of the British Museum (Natural History)

Dobigny G, Poirier P, Hima K, Cabaret O, Gauthier P, Tatard C, et al. (2011) Molecular survey of rodent-borne Trypanosoma in Niger with special emphasis on $T$. lewisi imported by invasive black rats. Acta Tropica 117:183-188

Dobson A, Lafferty KD, Kuris AM, Hechinger RF, Jetz W (2008) Homage to Linnaeus: How many parasites? How many hosts? Proceedings of the National Academy of Sciences of USA 105:11482-11489 
Drummond AJ, Ashton B, Buxton S, Cheung M, Cooper A, Duran C, et al. (2010) Geneious v5.5. Available: http://www.geneious. com

Dunn RR, Harris NC, Colwell RK, Koh LP, Sodhi NS (2009) The sixth mass coextinction: Are most endangered species parasites and mutualists? Proceedings of the Royal Society B: Biological Sciences 276:3037-3045

Dunne JA, Lafferty KD, Dobson AP, Hechinger RF, Kuris AM, Martinez ND, et al. (2013) Parasites affect food web structure primarily through increased diversity and complexity. PLoS Biology 11:e1001579

Gillespie TR, Chapman CA (2006) Prediction of parasite infection dynamics in primate metapopulations based on attributes of forest fragmentation. Conservation Biology 20:441-448

Hamilton PB, Gibson WC, Stevens JR (2007) Patterns of coevolution between trypanosomes and their hosts deduced from ribosomal RNA and protein-coding gene phylogenies. Molecular Phylogenetics and Evolution 44:15-25

Hartter J (2009) Attitudes of rural communities toward wetlands and forest fragments around Kibale National Park, Uganda. Human Dimensions of Wildlife 14:433-447

Hoare CA (1972) The Trypanosomas of Mammals, Oxford: Blackwell Scientific Publications

Keesing F, Holt RD, Ostfeld RS (2006) Effects of species diversity on disease risk. Ecology Letters 9:485-498

Koh LP, Dunn RR, Sodhi NS, Colwell RK, Proctor HC, Smith VS (2004) Species coextinctions and the biodiversity crisis. Science 305:1632-1634

May RM, Anderson RM (1991) Infectious Diseases of Humans: Dynamics and Control, Oxford: Oxford University Press

McCauley DJ, Salkeld DJ, Young HS, Makundi R, Dirzo R, Eckerlin RP, Lambin EF, Gaffikin L, Barry M, Helgen KM (2015) Effects of land use on plague (Yersinia pestis) activity in rodents in Tanzania. American Journal of Tropical Medicine and Hygiene 92:776-783

Mills JN, Yates TL, Ksiazek TG, Peters CJ, Childs JE (1999) Longterm studies of hantavirus reservoir populations in the southwestern United States: rationale, potential, and methods. Emerging Infectious Diseases 5:95-101

Milocco C, Kamyingkird K, Desquesnes M, Jittapalapong S, Herbreteau V, Chaval Y, et al. (2013) Molecular demonstration of Trypanosoma evansi and Trypanosoma lewisi DNA in wild rodents from Cambodia, Lao PDR and Thailand. Transboundary and Emerging Diseases 60:17-26

Molyneux DH (1969) Intracellular stages of Trypanosoma lewisi in fleas and attempts to find such stages in other trypanosome species. Parasitology 59:669-674

Noyes HA, Ambrose P, Barker F, Begon M, Bennet M, Bown KJ, et al. (2002) Host specificity of Trypanosoma (Herpetosoma) species: evidence that bank voles (Clethrionomys glareolus) carry only one $T$. (H.) evotomys $18 \mathrm{~S}$ rRNA genotype but wood mice (Apodemus sylvaticus) carry at least two polyphyletic parasites. Parasitology 124:185-190

Pedersen AB, Jones KE, Nunn CL, Altizer S (2007) Infectious diseases and extinction risk in wild mammals. Conservation Biology 21:1269-1279

Peppers LL, Carroll DS, Bradley RD (2002) Molecular systematics of the genus Sigmodon (Rodentia: Muridae): evidence from the mitochondrial cytochrome-b gene. Journal of Mammalogy 83:396-407
Pinto CM, Ocana-Mayorga S, Lascano MS, Grijalva MJ (2006) Infection by trypanosomes in marsupials and rodents associated with human dwellings in Ecuador. Journal of Parasitology 92:1251-1255

Pinto CM, Kalko EK, Cottontail I, Wellinghausen N, Cottontail VM (2012) TcBat a bat-exclusive lineage of Trypanosoma cruzi in the Panama Canal Zone, with comments on its classification and the use of the 18S rRNA gene for lineage identification. Infection, Genetics and Evolution 12:1328-1332

Pumhom P, Pognon D, Yangtara S, Thaprathorn N, Milocco C, Douangboupha B, et al. (2014) Molecular prevalence of Trypanosoma spp. in wild rodents of Southeast Asia: influence of human settlement habitat. Epidemiology and Infection 142:1221-1230

Randolph SE, Dobson ADM (2012) Pangloss revisited: a critique of the dilution effect and the biodiversity-buffers-disease paradigm. Parasitology 139:847-863

Salkeld DJ, Padgett KA, Jones JH (2013) A meta-analysis suggesting that the relationship between biodiversity and risk of zoonotic pathogen transmission is idiosyncratic. Ecology Letters 16:679-686

Salzer JS, Carroll DS, Williams-Newkirk AJ, Lang S, Peterhans JK, Rwego IB, et al. (2015) Effects of anthropogenic and demographic factors on patterns of parasitism in African small mammal communities. Parasitology 142:512-522

Sato H, Ishita K, Matsuo K, Inaba T, Kamiya H, Ito M (2003) Persistent infection of Mongolian jirds with a non-pathogenic trypanosome, Trypanosoma (Herpetosoma) grosi. Parasitology 127:357-363

Sato H, Takano A, Kawabata H, Une Y, Watanabe H, Mukhtar MM (2009) Trypanosoma cf. varani in an imported ball python (Python reginus) from Ghana. Journal of Parasitology 95:1029-1033

Stamatakis A, Ludwig T, Meier H (2005) RAxML-II: a program for sequential, parallel and distributed inference of large phylogenetic. Concurrency and Computation: Practice and Experience 17:1705-1723

Struhsaker TT (1997) Ecology of an African Rain Forest: Logging in Kibale and the Conflict Between Conservation and Exploitation, Gainesville, FL: University of Florida Press

Truc P, Büscher P, Cuny G, Gonzatti MI, Jannin J, Joshi P, et al. (2013) Atypical human infections by animal trypanosomes. PLoS Neglected Tropical Diseases 7:e2256

Verma A, Manchanda S, Kumar N, Sharma A, Goel M, Banerjee PS, et al. (2011) Case report: Trypanosoma lewisi or T. lewisi-like infection in a 37-day-old Indian infant. American Journal of Tropical Medicine and Hygiene 85:221-224

Verneau O, Palacios C, Platt T, Alday M, Billard E, Allienne JF, et al. (2011) Invasive species threat: parasite phylogenetics reveals patterns and processes of host-switching between non-native and native captive freshwater turtles. Parasitology 138:1778-1792

Wanyonyi MG, Ng'wena AGM, Ngeiywa MM (2011) Prevalence of Trypanosoma and Plasmodium species' parasites in small rodents of Kakamega Forest in western Kenya. African Journal of Health Sciences 19:61-67

Wenyon CM (1908) Report of the travelling pathologist and protozoologist. In: Third Report of the Wellcome Research Laboratories of the Gordon Memorial College, Balfour KAB (editor), London, UK: Tindall, Cox, pp 121-168

Wyatt KB, Campos PF, Gilbert MTP, Kolokotronis S-O, Hynes WH, DeSalle R, et al. (2008) Historical mammal extinction on Christmas Island (Indian Ocean) correlates with introduced infectious disease. PLoS One 3:e3602 
Johanna S. Salzer et al.

Young H, Griffin RH, Wood CL, Nunn CL (2013) Does habitat disturbance increase infectious disease risk for primates? Ecology Letters 16:656-663

Young HS, Dirzo R, Helgen KM, McCauley DJ, Billeter SA, Kosoy MY, et al. (2014) Declines in large wildlife increase landscape- level prevalence of rodent-borne disease in Africa. Proceedings of the National Academy of Sciences of USA 111:7036-7041

Zhang J, Kapli P, Pavlidis P, Stamatakis A (2013) A general species delimitation method with applications to phylogenetic placements. Bioinformatics 29:2869-2876 